\title{
Predicados de comunicação em português europeu: nominalizações e nomes autónomos
}

\author{
Sónia Reis ${ }^{1,3}$, Nuno Mamede ${ }^{2,3}$ \& Jorge Baptista ${ }^{1,3}$ \\ ${ }^{1}$ Universidade do Algarve, Faculdade de Ciências Humanas e Sociais, Faro, Portugal \\ ${ }^{2}$ Universidade de Lisboa, Instituto Superior Técnico, Lisboa, Portugal \\ ${ }^{3}$ INESC-ID Lisboa, Portugal, Human Language Technologies Lab, Lisboa, Portugal
}

\begin{abstract}
This paper provides an overview of the verbal and noun predicates involving the concept of communication and their distribution in the lexicon-grammar of European Portuguese. Two key concepts are used: (i) the agent-speaker semantic role (and other related roles, such as message, and addressee), associated with the subject syntactic slot of these predicates; and (ii) the possibility of the verb to enter a verbum dicendi construction, i.e., introducing direct speech.
\end{abstract}

Keywords: predicative noun, support-verb, nominalizations, European Portuguese, semantic role, lexicon-grammar

Palavras-chave: nome predicativo, verbo-suporte, nominalizações, português europeu, papel semântico, léxico-gramática

\section{Introdução}

Este artigo pretende contribuir para uma melhor delimitação e caracterização dos predicados de comunicação em português europeu, abrangendo não apenas os predicados verbais mas alargando o conceito às construções de nomes predicativos com verbo-suporte (M. Gross, 1981; Ranchhod, 1990; Baptista, $2005 a)$. Por predicado de comunicação entende-se, numa primeira aproximação, uma construção sintática que envolve 3 argumentos, com os seguintes papéis semânticos (os papéis semânticos são assinalados a negrito): um agente-locutor, uma mensagem e um interlocutor e de que é exemplo típico um verbo como confirmar, e.g.:

(1) O Pedro confirmou ao João que tinha feito isso

= (2) O Pedro deu confirmação ao João de que tinha feito isso

Muitos destes predicados verbais podem, ainda, apresentar uma construção de verbum dicendi (verbos "de dizer"), isto é, podendo aparecer como introdutores de discurso direto (Baptista, 2010); nesta construção, o sujeito do verbo desloca-se para a posição pós-verbal e a oração completiva complemento direto surge como o conteúdo da mensagem, em discurso direto; a expressão do complemento indireto nestas construções sem ser inaceitável é, no entanto, bastante rara, geralmente omitindo-se este complemento:

(3) "Fiz isso", confirmou o Pedro (ao João)

Em contrapartida, a construção nominal não parece dar origem a uma construção dicendi:

(4) ?/?* "Fiz isso", deu o Pedro (uma/a) confirmação (ao João)

Ora, o número de argumentos, o tipo de complementos e respetivos papéis semânticos das construções verbais e nominais que podemos associar a esta noção de predicado de comunicação resulta num conjunto bastante heterogéneo, sendo complexas as relações que se estabelecem, por um lado, entre as construções 
verbais e nominais equivalentes; e, por outro lado, a natureza semântica do predicado e a possibilidade de este entrar numa construção de verbum dicendi. Este artigo apresenta esta diversidade de situações com base na investigação sistemática do léxico-gramática de construções verbais (Baptista \& Mamede, 2020a) e nominais (Baptista \& Mamede, 2020b) do português europeu.

O artigo está organizado do seguinte modo: na Secção 2, faremos uma sucinta revisão de alguns trabalhos que se debruçaram sobre o tema; na Secção 3, descreveremos a metodologia utilizada; na Secção 4, serão apresentadas as principais construções (verbais) dos predicados de comunicação; segue-se-lhe a Secção 5, onde trataremos a construção de verbum dicendi; na Secção 6, por sua vez, temos as construções com nome predicativo. Por fim, na Secção 7, terminaremos com uma breve conclusão.

\section{Revisão da literatura}

O problema da definição de classes lexicais é complexo e não-trivial. A apresentação deste problema por Cançado e Gonçalves (2016, p. 374 ss.) é particularmente clarificadora e, naturalmente, baseia-se na hipótese de ser possível fazer uma definição de critérios que permitam considerar uma classe como um objeto linguisticamente coerente, que permita generalizações sistemáticas, e não um mero agrupamento de palavras, com base em meras semelhanças de significado. Justamente, o exemplo com que ilustram este tópico, é o da classe dos verbos que denotam fala. Retomando Pesetsky (1995), as autoras explicam a hipótese acima, considerando que:

"that there is no kind of syntactic generalization contrasting verbs that denote emission of loud speech (holler, shout) with verbs that denote emission of quiet speech (whisper, murmur). Conversely, the distinction between English verbs that denote a manner of speaking (holler, whisper) and verbs that denote a content of speaking (say, propose) seems to be relevant for their selection properties, since only the latter accept sentential complements: Mary said that she is hungry is well-formed, but *Mary whispered that she is hungry is not ${ }^{1}$. [...] Therefore, in the view adopted here, classifying verbs implies grouping them in clusters that share an array of semantic properties that have impact in their syntactic behavior, such as possible argument realizations, passivization, reflexivization, etc. [...] Thus, the semantic information carried by a verb is not just a list of idiosyncratic meanings, but contains types of meanings that are grammatically relevant."

A ideia de uma homologia ou, pelo menos, de uma correlação entre o significado e as propriedades formais das expressões linguísticas tem sido, de resto, o tema de fundo de numerosas tentativas de constituição de classes lexicais, sintática e semanticamente homogéneas.

Uma abordagem bastante popular da representação da semântica lexical baseia-se na definição dos papéis semânticos (ou temáticos) dos argumentos de uma dada construção a partir do significado denotado pelo elemento predicativo nuclear dessa predicação. Fillmore (1968) foi, provavelmente, a primeira pessoa a propor a noção de papéis semânticos como uma extensão do conceito gramatical de caso, conceito que tem merecido, ao longo dos anos, numerosas reflexões e reformulações (veja-se, entre outros o trabalho de Dowty, 1991) e diversas aplicações em linguística computacional (Gildea \& Jurafsky, 2002; para o português, na esteira de Bick

\footnotetext{
${ }^{1}$ Haverá que introduzir alguma nuance nesta afirmação já que a frase cuja inaceitabilidade se indica está, pelo contrário, abundantemente atestada, e.g. "he whispered in my ear that his sole sorrow was to have passed on before the windmill was finished. 'Forward, comrades!' he whispered." George Orwell, Animal Farm. Em português, uma frase equivalente com os verbos murmurar ou sussurrar seria perfeitamente possível, estando a construção com completiva suficientemente bem atestada para estes verbos: $O$ outro, muito secamente, não gostando decerto daquele interrogatório, murmurou que Proudhon era um autor de muita nomeada. (Eça de Queirós, Maias, Cap. 12); Alguém, ao meu lado, sussurrou que se chamava João Bosco (CETEMPúblico:par=ext757556-soc-92b-1).
} 
(2007), refira-se um trabalho recente sobre o português: Oliveira et al., 2021). Segundo Cançado e Gonçalves (ibidem, p. 376), o conjunto de papéis semânticos de cada construção constitui "the grammatically relevant semantic [structure]" desse elemento predicativo (um verbo, por exemplo):

"hence, verbs that show the same syntactic behavior, for example projecting arguments in a similar syntactic structure, should have the same semantic structure - the same list of thematic roles. In this way, thematic roles can be used to specify a verb class." (ibidem)

As autoras (p. 376) levantam, no entanto, várias objeções a esta abordagem à constituição de classes sintático-semânticas baseada em papéis semânticos, que podemos resumir nos seguintes pontos:

(i) a definição demasiado vaga dos papéis semânticos, que levanta dificuldades à sua aplicação, nomeadamente quanto à sua reprodutibilidade;

(ii) a necessidade de, por vezes, se ter de indicar dois papéis semânticos para a mesma posição argumental, nomeadamente, a escolha entre agente ou tema para o sujeito de um verbo como run (exemplo das autoras), consoante esse argumento seja preenchido por um nome humano ou não humano (presumimos);

(iii) a (aparente) inadequação do conceito de papéis semânticos para ligar diferentes níveis de granularidade na classificação de construções verbais; segundo as autoras:

"thematic roles do not seem to be the proper tool to deal with levels of granularity in verb classification. On the one hand, coarse-grained classes require very general, and few, roles; on the other hand, fine-grained classes require specific roles, and many in number; but, by assumption, arguments have only one such role." (ibidem)

Aliás, Cançado e Amaral (2017) também apresentam uma lista de papéis semânticos, ou "papéis temáticos" como os preferem designar, baseada, com algumas modificações, na proposta de Cançado (2012), e que compreende os seguintes papéis temáticos: agente; causa; paciente; tema; experienciador; resultativo; beneficiário; objeto estativo; locativo; e instrumento. Contudo, estas autoras alertam não só para a instabilidade terminológica que envolve este tipo de estruturas como também para a divergência de definições para os papéis temáticos propostos na literatura, o que, aliás, parece ser uma opinião partilhada por outros autores. Por isso, Cançado e Gonçalves (2016, p. 377) rejeitam esta abordagem de constituição de classes com base em papéis semânticos, conquanto "we will keep using thematic role labels in our discussion as a descriptive tool, since they are the most common way of describing semantic relations."

As objeções levantadas são bem conhecidas, mas poderão, quanto a nós, ser resolvidas (pelo menos parcialmente) se se introduzir nesta equação os seguintes aspetos:

(i) adotar um método de atribuição de papéis semânticos aos argumentos de um dado predicado que permita controlar a eventual vagueza da sua definição, ao mesmo tempo que

(ii) se estabelece uma lista de papéis suficientemente genérica e de dimensões moderadas/controladas;

(iii) ser possível admitir que a definição de papéis semânticos (mais abstratos) que, para certos predicados semânticos, possa considerar não ser relevante certos traços distribucionais, que noutras situações são fundamentais.

Quanto a este último aspeto, por exemplo, a natureza (não) humana/ (não) animada do elemento que preenche uma dada posição argumental, pode ser ignorada por ser irrelevante, em casos como o complemento direto de ver; ou a natureza semântica (origem, destino, percurso) do complemento locativo de verbos como ir.

$\mathrm{Na}$ abordagem que aqui adotamos, a determinação do papel semântico (a interpretação) que um dado constituinte desempenha numa frase elementar relativamente ao elemento predicativo de que depende resulta 
da comparação dessa interpretação com a que um constituinte idêntico exibe quando ocupa uma dada posição sintática de um elemento predicativo considerado típico do papel a atribuir. Assim, por exemplo, o sujeito de um verbo como falar ou dizer desempenha, de forma típica, o papel de agente-locutor (pessoa que fala) valor que é idêntico ao do sujeito de um verbo da mesma classe, como tergiversar, cujo significado terá, talvez, uma interpretação talvez mais marginal dentro dessa classe, mas que, entre outras propriedades, admite a construção de verbo dicendi:

«Ó senhor deputado», tergiversou Cravinho, [...] (CETEMPúblico: par=ext1326493-pol-96b-2).

Dizemos que este papel semântico é relevante para a descrição gramatical porque permite delimitar conjuntos de elementos predicativos mais ou menos extensos (verbos plenos e construções com nome predicativo e verbo-suporte, neste caso) e que apresentam propriedades distribucionais e estruturais semelhantes. A determinação desses conjuntos é objeto de levantamento sistemático no léxico e deverá, espera-se, conduzir à constituição de classes léxico-sintático-semânticas relativamente homogéneas. Contudo, a constituição dessas classes não resolve, porém, a irredutível idiossincrasia, intrínseca ao léxico, o que terá impacto variável nas diferentes aplicações que delas se pretender fazer.

Neste caso em concreto, o processo de atribuição de papel semântico de agente-locutor, resulta em várias centenas de verbos, entre outras propriedades, selecionarem igualmente uma completiva para complemento direto, que é interpretada como o conteúdo da mensagem comunicada, e, em certos casos, um complemento indireto (dativo), conceptualizado como o interlocutor a quem o sujeito se dirige verbalmente. Esta técnica tem a vantagem de se basear em juízos de aceitabilidade sobre frases reais e não sobre construtos mais ou menos abstratos, de difícil verificação empírica. Diga-se, de resto, que este tipo de juízos contrastivos é extremamente operativo, como já alertara M. Gross (1976, 1988), e produzem resultados muito mais finos do que os juízos formulados de forma absoluta sobre frases isoladas ou sobre interpretações difusas e difíceis de controlar experimentalmente.

Em segundo lugar, o conjunto de papéis semânticos aqui considerado (v. Baptista \& Mamede, 2020a) retém apenas os tipos mais usuais e já contemplados na literatura, sugerindo até alguma simplificação. Por exemplo, é possível, como dissemos, ignorar a distinção humano/não-humano para a posição de sujeito de cerca de 300 construções verbais, nomeadamente para numerosos verbos de movimento, como correr, em que a distinção humano/não-humano-animado (animal) parece irrelevante (O Pedrolo leopardo corre). Em alguns casos, essa variação resulta de processos metafóricos, mais ou menos lexicalizados (e.g. funcionar: $O$ Pedro não funciona bem de manhã sem café; A máquina não funcionava bem $)^{2}$.

Finalmente, esse tipo de método é mais consentâneo com o quadro teórico aqui adotado, o da gramática transformacional de operadores, nomeadamente porque: (a) a constituição de classes, concretamente de classes de operadores, é baseada, sobretudo, em critérios distribucionais; (b) as transformações (ou, nos termos de Levin (1993), adotados pelas autoras as alternâncias, do ing. alternations) conservam a informação das formas de frase de base, permitindo a constituição de classes com comportamentos sintáticos homogéneos.

Embora os predicados de comunicação desempenhem um papel importante na língua, a sua definição não é trivial. Vários são os autores que têm vindo a desenvolver estudos sobre o que aqui se designa por predicados de comunicação. Como já se referiu anteriormente, neste artigo, estes predicados podem ser constituídos por

\footnotetext{
${ }^{2}$ Nesses casos, a solução descritiva adotada procurou evitar o excessivo desdobramento lexical destas construções e consistiu em atribuir papéis duplos, e.g. agente-objeto (correr) ou experimentador-objeto (funcionar), aos argumentos, admitindo ambos os empregos como em grande medida semanticamente semelhantes e deixando a seleção do papel preciso dependente da natureza distribucional (humano/não humano) do elemento que preencher essa posição sintática. Note-se, ainda que, no quadro conceptual aqui adotado, não se considera o papel de tema (atribuído em geral a sujeitos não humanos) e usa-se o conceito de objeto tanto para a posição de sujeito como de complemento.
} 
verbos que representam um ato de comunicação verbal ou mesmo por nomes predicativos, por vezes, resultantes de um processo de nominalização desses mesmos verbos, que exprimem um ato dessa mesma natureza.

Em relação aos verbos, destacamos o trabalho desenvolvido por Levin (1993) que apresenta uma classificação formal dos verbos do inglês, orientada a partir da investigação das propriedades sintáticas semanticamente relevantes, que permitiriam o estabelecimento de diversas classes de verbos (cf. pp. 15-16). Nessa classificação, os verbos encontram-se distribuídos por 49 classes 'semanticamente coerentes' ("semantically coherent") e 'sintaticamente relevantes' ("syntactically relevant"). Dito de outra forma, apresentam-se classes semânticas de verbos que partilham de um conjunto de propriedades sintáticas, teoricamente determináveis a partir desse agrupamento semanticamente coerente. Destas classes, interessa-nos aqui a que representa os 'verbos de comunicação e transferência de ideias', subdividida nas seguintes subclasses: (i) verbos de transferência de uma mensagem (e.g. ask, cite); (ii) verbos de contar "tell" (tell); (iii) verbos de maneira de falar (scream, murmur); (iv) verbos de instrumento de comunicação (to e-mail, phone); (v) verbos de falar "talk verbs" (speak e talk); (vi) verbos de conversar (conversa informal), "chitchat" (argue, chat); (vii) verbos de dizer "say verbs" (confess, say); (viii) verbos de reclamar (complain, grumble); e (ix) verbos de aconselhar (advise, alert). De notar que os verbos alistados sob cada uma destas classes não pretendem ser representativos (cf. p. 202) e apresentam um número variável de verbos, entre apenas 1 (classe (ii), tell) a 77 (classe (iii), verbs of manner of speaking), contabilizando um total de 167 verbos.

No que respeita ao português do Brasil, estes verbos também receberam a atenção de vários autores. Veja-se, por exemplo, a este propósito, o que Garcia (2011) nos diz, no capítulo dedicado aos discursos direto e indireto, acerca dos verbos designados por verbos dicendi (de dizer) ou declarandi (de declarar), e muitos dos seus substitutos, designados por verbos sentiendi (de sentir). Para Garcia (2011), os verbos dicendi ou de elocução têm como principal função indicar o interlocutor que está com a palavra e pertencem, grosso modo, às seguintes áreas semânticas: (i) de dizer (e.g. declarar); (ii) de perguntar (interrogar); (iii) de responder (replicar); (iv) de contestar (negar); (v) de concordar (anuir); (vi) de exclamar (gritar); (vii) de pedir (solicitar); (viii) de exortar (aconselhar); e (ix) de ordenar (mandar). O autor não especifica, contudo, nenhum critério (formal, sintático) para a constituição destes tipos semânticos. Para além destes, que são os mais comuns e de sentido mais geral, Garcia alerta para o facto de existirem outros verbos de sentido mais específico, também "caracterizadores da fala", que são utilizados por muitos autores, em especial "na literatura do nosso século", por exemplo, soluçar ou vociferar. Garcia (ibidem) refere também que há uma classe bastante numerosa de verbos de elocução que expressam estados de espírito, reação psicológica da personagem, emoções - os verbos de sentir - que poderiam, por analogia com os verbos dicendi, ser denominados sentiendi (e.g. gemer; queixar-se). Estes verbos apareceriam, então, antepostos aos verbos de dizer propriamente ditos, e.g. "explode, dizendo", porque, segundo o autor, têm um verbo dicendi oculto. O autor liga este comportamento a um conceito de transitividade, que, segundo ele marcaria os verbos dicendi, ao passo que os verbos sentiendi não admitiriam a ideia de transitividade:

“constituem uma espécie de vicários dos dicendi, com função predominantemente caracterizadora de atitudes, de gestos ou qualquer manifestação de conteúdo psíquico, e quando o narrador sente que não admitem de forma alguma a ideia de transitividade, eles vêm, de regra, antepostos à fala, como no caso de "encavacou" e "explode"." (idem: 77-78).

Para além de indicar o interlocutor que está com a palavra, uma outra função dos verbos dicendi, de acordo com este autor, consiste em permitirem a junção de orações adverbiais, na sua maioria orações reduzidas de gerúndio, ou de expressões de valor adverbial com que o narrador realça a fala da personagem, destacando-lhe uma reação física ou psíquica.

Ainda para o português do Brasil, Perini (2015), ao descrever as valências verbais (conjunto de construções em que um verbo pode ocorrer), com vista à elaboração de um dicionário de valências verbais do PB, dá conta 
de que as construções com verbos dicendi nem sempre apresentam a típica construção agente (locutor), mensagem e destinatário. Desta forma, o autor analisa o sujeito desses verbos enquanto agente mas prefere deixar as distinções a cargo do processo de elaboração, com base na semântica do verbo, como refere (cf. p. 89). Também Couto e Perini (2016) discutem o termo de verbo dicendi, revisitando os conceitos que vários autores associam e distinguindo, por um lado, o conceito de predicado semântico de tipo declarativo e, por outro lado, a construção de verbo dicendi, enquanto forma sintática introdutora de discurso direto (a mensagem). Esta distinção também nos parece útil, estando aliás, subjacente à análise de Baptista (2010).

Costa e Freitas (2017), por seu turno, identificam 293 verbos de elocução num estudo descritivo com base em corpora. De uma lista inicial de 58 verbos de elocução, e com o objetivo de ampliar essa lista, foram utilizados seis verbos que serviram como "semente" - os verbos admitir, contar, continuar, dizer, perguntar e responder - em oito padrões léxico-sintáticos característicos desta classe de verbos. Por seu turno, e com o objetivo de auxiliar na tradução, Costa e Freitas (2019) realizam um estudo sobre os "verbos de elocução" (os 293 verbos já referidos em Costa e Freitas, 2017), distribuídos de acordo com o sentido que apresentam. As autoras acabam por dividir esses verbos nos seguintes 11 grupos: (i) concordância e discordância; (ii) continuidade e conclusão; (iii) declaração; (iv) destaque; (v) emoções e exclamações; (vi) hesitação; (vi) palpites e certezas; (viii) pedido, ordem e sugestão; (ix) pergunta; (x) resposta; e (xi) outros (i.e., que não se incluem nos tipos semânticos anteriores). As autoras concluem, no entanto, que a distribuição de verbos de elocução por classes de sentido não é uma tarefa fácil, e, dadas as dificuldades encontradas em determinar o seu significado preciso, acabam por considerá-la uma tarefa "impossível” (cf. p. 510).

Também as Wordnets poderão ser um contributo para a delimitação do conjunto de verbos de comunicação. Isto porque estas ontologias lexicais pretendem constituir conjuntos de palavras (synsets) de uma mesma classe gramatical que estabelecem uma relação de sinonímia (e outras relações semânticas) entre si. Ora, para o português, já se encontram disponíveis várias destas bases de dados ${ }^{3}$, nomeadamente, as ontologias WordNet.PT (Marrafa, 2002), Onto.PT (Oliveira \& Gomes, 2014), PAPEL (Oliveira, Santos \& Gomes, 2010), PULO (Simões \& Guinovart, 2014), TeP (Dias-da-Silva \& Moraes, 2003; Maziero et al., 2008), e OpenWordNet-PT (Paiva, Rademaker \& de Melo, 2012). A título meramente ilustrativo, refira-se que a Onto.PT, uma das wordnets livres do português, apresenta mais de 100 synsets associados ao verbo falar (e.g. afirmar, contar, conversar, dialogar, emitir).

Os verbos que exprimem predicados de comunicação também ocorrem nas chamadas "expressões cristalizadas" (ECs) ou expressões fixas, embora com pouca expressão, como constatam Sousa e Vale (2006). Os autores dão conta de 46 ECs com verbos de comunicação (e.g. Ele fala pelos cotovelos), mas apenas 21 destas com verbos diferentes. Acabam por concluir que as ECs que apresentam verbos de comunicação são pouco frequentes nos registos mais formais (e.g. romances), e colocam a hipótese de se encontrar mais destas expressões noutros tipos de corpora, como, por exemplo, em jornais ou revistas.

No que respeita ao português europeu, o Dicionário Terminológico para consulta em linha (DT) ${ }^{4}$, na secção dedicada ao discurso direto, alude aos verbos dicendi, apresentando como exemplos os verbos dizer, responder, contar, e afirmar, e indicando que estes "significam a realização por um sujeito de um acto de comunicação verbal".

Já em Cunha e Cintra (1984) pouco se adianta acerca desta classe de verbos. São referidos, igualmente na secção dedicada aos discursos direto e indireto, sob os termos verbos dicendi e verbos declarativos e são apenas apresentados alguns exemplos desses mesmos verbos, não chegando a ser definidos nem serem dadas quaisquer indicações quanto às suas propriedades. Por sua vez, Duarte (2020), no capítulo dedicado ao discurso relatado,

\footnotetext{
${ }^{3}$ http://wordnet.pt/

${ }^{4}$ https://dt.dge.mec.pt/
} 
apresenta-nos uma secção sobre verbos introdutores de relato de discurso. Segundo a autora, estes verbos, por vezes acompanhados de outros complementos,

"tendem a caracterizar a "voz" que introduzem ou comentam, e revelam-se essenciais para se poder conhecer melhor a situação da enunciação do enunciado relatado com toda a pluralidade de matizes que inclui: entoação, efeitos de pausa, indicações de mise en scène vocal e paralinguística, etc.” (p. 2604).

A autora refere ainda que os verbos dicendi (ou verbos de comunicação): “exprimem atividades verbais dos sujeitos falantes, especificamente comunicativas, aquelas cujo objetivo prioritário é transmitir uma informação" e acrescenta que esses verbos "apresentam um sujeito e um complemento indireto humanos (nem sempre, no entanto, apresentam este complemento), e que o complemento direto é o discurso relatado; no discurso direto, de forma direta e, no discurso indireto, sob a forma de uma oração subordinada completiva" (ibidem). Para a autora, é necessária a articulação entre critérios sintáticos e critérios de natureza semântica para se poder descrever os verbos de comunicação. Veja-se, pois, a proposta de tipologia semântico-pragmática dos verbos introdutores de discurso que apresenta: (i) assertivos (e.g. afirmar, declarar); (ii) expressivos (e.g. censurar, lamentar); (iii) rogativos (e.g. inquirir, perguntar); (iv) diretivos (e.g. ordenar, pedir); (v) perlocutórios (e.g. ameaçar, avisar); (vi) promissivos/comissivos (e.g. jurar, prometer); (vii) verbos que revelam a adesão forçada do locutor à verdade que o interlocutor defende (e.g. confessar); (viii) verbos de qualificação do dizer (organizados em 4 subgrupos: (1) verbos metafóricos (e.g. rosnar, rugir); (2) verbos que referem o tom, qualificam o estilo ou maneira de falar do locutor, com ressonâncias onomatopaicas (e.g. balbuciar, bichanar); (3) verbos que referem a maneira de falar, embora já afastados da descrição fónica (e.g. aludir, negar); e (4) verbos que pressupõem uma intervenção anterior de um dos interlocutores (e.g. acrescentar, argumentar).

Baptista (2010), por seu turno, apresenta um estudo sobre as construções dos verbos dicendi, verbos estes pertencentes às classes 06 e 09 da base de dados do ViPEr, subjacente ao Dicionário gramatical de verbos do português (doravante, DGVP; Baptista \& Mamede, 2020a). Trata-se de construções com sujeito humano e completiva-complemento direto (classe 06), ou construções que, além destes constituintes, apresentam ainda um complemento indireto (dativo; classe 09). O autor demonstra que a maior parte dos verbos dicendi não apresenta a estrutura típica de verbos como dizer e pensar, à medida que nos afastamos do significado literal desses verbos, sendo assim necessária uma descrição mais fina destas estruturas. Este dicionário apresenta, na versão atual, cerca de 7.000 entradas (construções sintáticas distintas) que correspondem aos verbos mais frequentes do português europeu. Cada emprego (ou construção) verbal constitui uma entrada distinta, a que estão associadas as respetivas propriedades estruturais (número e tipo de complementos), distribucionais (humano/não humano; construções completivas, etc.) e transformacionais (p. ex. passiva). Para cada posição argumental foi ainda associado o respetivo papel semântico, a partir de um conjunto de 37 papéis semânticos básicos, determinado por Talhadas et al. (2013) e Talhadas (2014). As construções verbais estão organizadas em cerca de 70 classes sintático-semânticas, definidas por um conjunto de propriedades semelhantes. O trabalho de Talhadas (2014) permitiu não só o estabelecimento de um conjunto relativamente "consensual e de uso geral" de papéis semânticos como também permitiu construir um módulo de anotação de papéis semânticos que se encontra integrado na cadeia de Processamento de Linguagem Natural STRING (Mamede et al., 2012) ${ }^{5}$. O módulo é composto por cerca de 200 regras de correspondência de padrões para a marcação de sujeito e dos complementos essenciais das construções verbais com os respetivos papéis semânticos e permite ainda a atribuição de papéis a outros constituintes sintáticos.

\footnotetext{
${ }^{5}$ https://string.hlt.inesc-id.pt/
} 
Em relação aos predicados nominais, para o português europeu, indicamos os estudos já desenvolvidos por Ranchhod (1990), que faz a descrição das construções com o verbo-suporte estar Prep + nome predicativo; o estudo desenvolvido por Baptista (2005a), onde se descrevem as construções com o verbo-suporte ser de + Npred; e a descrição das construções com o verbo-suporte fazer + Npred, por Chacoto (2005). Todos estes trabalhos apoiados no modelo teórico metodológico do Léxico-Gramática (M. Gross, 1981, 1996), desenvolvido no quadro da gramática transformacional de operadores de Z. S. Harris (Harris, 1991). Para o português do Brasil, por seu turno, destacamos os trabalhos de Scher (2004), uma descrição das construções com o "verbo leve" dar e nominalizações em -ada; Dias de Barros (2014), que faz a descrição e classificação dos predicados nominais com o verbo fazer; Rassi (2015), que faz a descrição, classificação e processamento automático das construções com o verbo dar; o de Santos (2015), que descreve as construções com o verbo-suporte ter; e, ainda, o trabalho de Calcia (2016), com a descrição dos pares de construções conversas (cf. G. Gross, 1989) com verbo-suporte e nome predicativo como, por exemplo, O João deu uma ajuda ao Pedro / O Pedro recebeu uma ajuda do João. É a partir dos dados destes estudos que se tem vindo a construir uma base de dados que procura compilar as construções nominais (pelo menos as mais usuais) do português europeu, trabalho ainda em curso, contendo já cerca de 6.000 nomes predicativos, e cujos primeiros resultados, sobre o processamento das transformações que estas autorizam, se pode ver em Baptista e Mamede (2020b). Foi igualmente esta base de dados que serviu de fonte para este estudo.

\section{Métodos}

O objetivo deste artigo é contribuir para uma melhor caracterização dos predicados de comunicação em português europeu, ou seja, as construções verbais que envolvem tipicamente um sujeito agente-locutor (ou que fala) e compará-las com as construções de nomes predicativos e verbo-suporte que expressam esse mesmo tipo de predicados.

Para tal, socorremo-nos da base de dados de construções verbais do português europeu (ViPEr) (Baptista, 2012; 2013), enriquecido com informação quanto aos papéis semânticos das posições argumentais (Talhadas, 2014), na sua versão atual (Baptista \& Mamede, 2020a). Esta base de dados serve de léxico-gramática ao sistema de processamento de linguagem natural STRING (Mamede et al., 2012). Fizemos também uso dos resultados preliminares (Baptista \& Mamede, 2020b) do trabalho (em curso) de recenseamento sistemático das construções de nomes predicativos, feito a partir das suas descrições mais recentes (Ranchhod, 1990; Baptista, 2001, 2005; Chacoto, 2005; Santos, 2015; Dias de Barros, 2014; Rassi, 2015).

Num primeiro momento, identificámos as construções verbais relevantes para este estudo, nomeadamente, as que apresentam um argumento caracterizado como agente-locutor (do ing. agent-speaker). Ao todo, encontramos 309 verbos marcados com este papel semântico na posição sintática de sujeito (este papel semântico não ocorre noutras posições sintáticas). O número de construções representa $4,4 \%$ das construções presentes na base de dados (\#7.010). Os verbos distribuem-se por 22 construções léxico-sintáticas (classes) diferentes, como se apresenta na Tabela 1. No final deste artigo, apresentamos uma tabela com uma descrição sucinta destas classes.

\begin{tabular}{|c|c|c|c|c|c|}
\hline Classe & Verbos & Classe & Verbos & Classe & Verbos \\
\hline $\mathbf{0 6}$ & $33(11 \%)$ & $\mathbf{4 1}$ & $9(3 \%)$ & $\mathbf{3 5 S}$ & $13(4 \%)$ \\
\hline $\mathbf{0 7}$ & 1 (aludir) & $\mathbf{0 9 C}$ & $31(10 \%)$ & 36DT & $5(2 \%)$ \\
\hline $\mathbf{0 8}$ & $5(2 \%)$ & $\mathbf{0 9 I}$ & $125(40 \%)$ & 39D & 1 (chamar) \\
\hline
\end{tabular}




\begin{tabular}{|c|c|c|c|c|c|}
\hline $\mathbf{1 0}$ & $2(1 \%)$ & $\mathbf{0 9 R}$ & $2(1 \%)$ & $\mathbf{3 9 S}$ & $7(2 \%)$ \\
\hline $\mathbf{1 1}$ & 1 (chamar) & $\mathbf{3 2 C}$ & $2(1 \%)$ & $\mathbf{3 9 T}$ & $19(6 \%)$ \\
\hline $\mathbf{1 3}$ & $13(4 \%)$ & $\mathbf{3 2 H}$ & $21(7 \%)$ & $\mathbf{4 2 S}$ & 1 (falar) \\
\hline $\mathbf{1 6}$ & $2(1 \%)$ & $\mathbf{3 2 R}$ & $6(2 \%)$ & TOTAL & $\mathbf{3 0 9}$ \\
\hline $\mathbf{4 0}$ & 1 (participar) & $\mathbf{3 5 R}$ & $9(3 \%)$ & & \\
\hline
\end{tabular}

Tabela 1. Distribuição das construções com sujeito agente-locutor por classe ViPEr. As percentagens referem-se ao total de construções com este papel semântico.

Destes empregos, considerámos necessário descartar deste estudo algumas entradas:

- 19 construções regularmente derivadas por prefixação, e.g. contrapropor (09C), desaconselhar (09C), pré-anunciar (09I), reafirmar (09I), em que pelo menos uma das construções do verbo da forma de base não sofre alterações ${ }^{6}$;

- 45 construções consideradas pouco usuais, e.g. tachar (39T: O Pedro tachou o João de trinca-espinhas), pelo menos quando comparadas com outras construções do mesmo verbo, e.g. prefixar (09C) no sentido de 'prescrever'; ou que não atingiram o limiar de frequência mínimo no corpus CETEMPúblico (Rocha \& Santos, 2000), que serviu de base à constituição do ViPEr, para serem integrados no sistema STRING, e.g. salmodiar (09I) ${ }^{7}$.

- 5 construções (dizer, 09C, 09I; falar, 091 e negar, 09C, 09I) cuja duplicação foi considerada necessária na base de dados por razões meramente formais.

Trataremos, mais adiante (§6), das construções com nome predicativo e verbo-suporte, altura em que apresentaremos os métodos e resultados do levantamento dos predicados de comunicação deste tipo.

\section{Principais construções dos predicados de comunicação}

A distribuição dos verbos por classes sintáticas é, para um certo número delas, natural e esperável. Assim, por exemplo, as classes 09x correspondem às construções com sujeito humano, complemento direto frásico (ou oracional) e um complemento indireto humano (dativo), distinguindo-se as classes quanto à restrição que o verbo impõe ao modo da completiva ('C': conjuntivo, 'I': indicativo) ou a sua natureza interrogativa ('R') e de que são exemplos característicos ordenar $(\mathbf{0 9 C})$, dizer $(\mathbf{0 9 I})$ e perguntar $(\mathbf{0 9 R})$.

De um modo geral, as construções marcadas com agente-locutor apresentam uma construção de verbum dicendi (Vdic), isto é, de verbo introdutor de discurso (Baptista, 2010):

\footnotetext{
${ }^{6}$ A lista completa destes verbos: contrapropor (09C), desaconselhar (09C), pré-anunciar (09I), reafirmar (patient), reapresentar (39T), rebatizar (39T), reconfirmar $(\mathbf{0 6})$, recontar $(\mathbf{0 9 I})$, redefinir $(\mathbf{3 2 C})$, redizer $(\mathbf{0 9 I})$, reexplicar $(\mathbf{0 9 I})$, reimpor $(\mathbf{0 9 C})$, reinsistir $(\mathbf{4 1})$, relembrar (09I), renomear (39T), repropor (09C), ?requerer (09C), subintitular (39T), telecomunicar (09I).

${ }^{7}$ A lista completa destes verbos: apodar (39T), apostrofar (39T), avocar (06), chamar (38LD), cognominar (39T), colocar (06), concretizar (06), contra-indicar (09C), demandar (09C), derrogar (06), despicar (35S), epitetar (39T), epitomar (39T), epitomizar (39T), falar (35LD), falar (35R), falar (35R), fanfarronar (09I), galhofar (35S), justificar (32R), maldizer (08), mexericar (35S), murmurejar (09I), parlar (42S), parolar (35S), pleitear (09C), predefinir (06), prefixar (09C), prelecionar $(\mathbf{0 6})$, prelecionar $($ (35R), pronunciar $($ (39T), prosar (35S), querelar (35S), recobrar $(\mathbf{0 9 C})$, repostar $(\mathbf{0 9 I})$, requestar $(\mathbf{0 9 C})$, requestar $(\mathbf{3 6 D T})$, resenhar $(\mathbf{0 9 I})$, respostar $(\mathbf{0 9 I})$, sair (35R), salmodiar (09I), sarrazinar (32H), tachar (39T), trejurar (09I), trombetear (09I).
} 
(5) “Não posso ir a Lisboa”, disse o Pedro

Contudo, um número não negligenciável destes verbos (\#73) não parece admitir a construção Vdic, distribuindo-se por 17 classes léxico-sintáticas diferentes. Disto falaremos mais adiante.

Por outro lado, alguns dos resultados obtidos não eram exatamente os esperados. Não se esperava encontrar este tipo de predicados na classe 07, por exemplo. Esta classe apresenta uma construção preposicional com sujeito humano e completiva infinitiva na posição de complemento preposicionado, introduzido pela preposição $a$, e.g.:

(6) O Pedro aprendeu a andar de bicicleta

Ora, o único caso da classe $\mathbf{0 7}$ com um agente-locutor na posição de sujeito diz respeito ao verbo aludir cujo exemplo é:

(7) O Pedro aludiu a (o facto de) isso ter acontecido assim

A classe 08, por sua vez, também apresenta alguns exemplos com agente-locutor. Veja-se, a propósito, a construção do verbo gabar e argumentar em:

(8) O Pedro gaba-se de ter feito aquilo

(9) O Pedro argumentou contra as acusações que lhe faziam

Estes exemplos têm efetivamente um sujeito que fala e uma completiva, mas a sua classificação em $\mathbf{0 8}$ indica que normalmente não teriam complemento indireto. A observação da natureza de agente-locutor do seu sujeito permite considerar a sua reclassificação, nomeadamente, de gabar em 09I (O Pedro gabou-se ao João de que tinha feito aquilo), ou, no caso de argumentar ( $O$ Pedro argumentou com o João contra essas acusações), na classe $\mathbf{4 0 .}$

Outros exemplos destes resultados não previstos são os das construções com os verbos arengar e barafustar, da classe 10, aqui apresentadas:

(10) O Pedro barafustou que não queria ir ao cinema

(11) O Pedro arengou que a Ana devia fazer isso

e que não conseguimos construir (nem encontramos atestações) com complemento indireto, ainda que admitam um complemento com Nhum percebido como o paciente (eventualmente o interlocutor).

Já da classe 11, temos o exemplo do verbo chamar na construção:

(12) O Pedro chamou o João a fazer isso. (cp. O PR chamou Fulano a formar governo)

que poderíamos talvez considerar uma extensão do conceito de locutor. Neste caso, o primeiro complemento tem o papel temático de paciente, e não de interlocutor, como acontece em verbos como dizer; também, por isso, não se trata claramente de um predicado de comunicação, não havendo nenhum argumento com o valor de mensagem. Um outro exemplo, mas da classe 13 é:

(13) O Pedro questionou o João acerca de um assunto 
também este com uma completiva. É pouco usual encontrar-se predicados de comunicação nesta classe. Além disso, à semelhança de uma classe anterior, nem sempre é claro se o complemento é um interlocutor; podendo ser um paciente. Na classe 16, temos dois exemplos de uma construção cujo sujeito pode também ser considerado uma extensão do papel de locutor. Um desses exemplos é a seguinte construção de contrapor:

\section{(14) O Pedro contrapôs que o João queria isso ao que foi dito}

Na classe 32H temos várias construções com dois humanos, com sujeito locutor e em que o primeiro complemento desempenha um papel difícil de determinar com precisão, já que ora é interpretado preferencialmente como interlocutor (cumprimentar, felicitar, interpelar, repreender, vaiar), ora parece interpretar-se mais como um paciente (e.g. caluniar, chagar, contradizer, desdizer), sem deixar de denotar a pessoa a quem o sujeito se dirige; nestes casos, apenas parece mais evidente que a pessoa é o objeto da ação. Já nos casos de elogiar e gabar, ainda que o sujeito seja claramente interpretado como locutor, o complemento admite um nome concreto como objeto (v.g. elogiar o vestido, gabar o carro; neste caso, estas construções deveriam ter sido classificadas como 32C, já que $\mathbf{2 3 H}$ inclui apenas as construções com dois argumentos humanos.). Esta última configuração de papéis diverge de uma ideia típica de um predicado de comunicação.

Por seu turno, na classe 32R, temos com os verbos trautear e cantarolar uma extensão dos predicados de comunicação, já que apenas apresentam um complemento objeto. É também nesta classe que se encontra a construção de falar (uma língua).

$\mathrm{Na}$ classe 35R, temos apenas um pequeno conjunto de verbos com sujeito locutor e que apresentam em posição de complemento os papéis semânticos de interlocutor (abrir-se com, ralhar com, refilar com, respingar com), e de tópico (discorrer, opinar e prelecionar sobre). Noutros casos, parece mais adequada a atribuição dos papéis de paciente (blasfemar contra, clamar por, gritar com), conquanto, neste último caso, a distinção entre ele e os casos de ralhar e seus sinónimos, que vimos mais acima, pareça mais difícil de estabelecer. Finalmente, registamos ainda nesta classe uma construção com objeto (sair-se com uma frase/palavra/piada) e duas que foram descritas como instrumento: falar ao telefone/telemóvel/microfone (eventualmente a incluir nas construções idiomáticas) e falar em <língua >.

Encontramos também construções simétricas (Baptista, 2005b) que relevam do modelo de predicado de comunicação, desde logo o próprio verbo comunicar: O Pedro comunica com a Ana <regularmente>, mas também, entre outros, cavaquear, conferenciar, conversar, coscuvilhar, dialogar, discutir, fofocar, galhofar, mexericar ou tagarelar. Nestes casos, na classe 35S, há uma relação de simetria entre o sujeito e o complemento, pelo que os respetivos papéis semânticos são (reciprocamente) locutor e interlocutor.

Encontra-se na classe 36DT um pequeno conjunto de verbos em que o significado das respetivas construções denota um ato comunicativo e implica tanto um sujeito locutor (denunciar, ditar, indicar; encomendar, requisitar) como um complemento indireto (dativo) interlocutor, ainda que em alguns casos, como sucede com encomendar e requisitar, a ação não envolva necessariamente um ato de fala.

Finalmente, um número bastante importante (quase 40) de construções ditas transitivas-predicativas (classe 39T) estão de algum modo associadas à noção de sujeito locutor. Trata-se de construções que envolvem a atribuição de uma designação ou atributo a um paciente ou a um objeto (adjetivar, batizar, alcunhar, apelidar, denominar, intitular, qualificar, rotular, tratar):

\section{(15) O Pedro batizou o menino como/de “João” (= com o nome de “João”)}

Neste conjunto, salientam-se as duas construções sintáticas do verbo chamar, a da classe 39T, idêntica à do exemplo anterior, e o caso isolado da construção 39D, com um complemento indireto: 
(i) O Pedro chamou o João de parvo (39T) O Pedro chamou parvo ao João (39D)

A par desta construção (i), sinónima de apodar/rotular e com valor disfórico, encontramos a mesma interpretação (ii) de batizar/nomear, que vimos em (14), e em ambas as formas:

(ii) O Pedro chamou o menino de João (39T) O Pedro chamou João ao menino (39D)

Não conhecendo forma de ligar transformacionalmente as duas construções, relação que, de resto, não é produtiva na classe, estas construções foram desdobradas lexicalmente, apesar das semelhanças que se observam entre elas, incluindo as duas interpretações (i) e (ii).

Vimos, assim, que o conceito de predicado de comunicação pode ser descrito com alguma confiança recorrendo ao papel semântico de agente locutor. Estes predicados envolvem frequentemente um argumento que corresponde ao conteúdo da mensagem e outro argumento que designa o interlocutor. Vimos também que, embora alinhados com estes predicados, há igualmente um número importante de outros verbos que não selecionam um complemento indireto interlocutor, havendo um segundo argumento com valor de paciente ou de objeto. A diversidade de classes formais em que este tipo de predicados se deixa classificar também deixa entrever a variedade de significados que o conceito de comunicação abrange.

Esta heterogeneidade de perfis semânticos (considerando os papéis associados a cada predicado), mesmo dentro de construções sintaticamente semelhantes (a mesma classe léxico-sintática) torna mais complexo um tratamento unificado dos predicados de comunicação e está, provavelmente, na origem das dificuldades observadas nos trabalhos relacionados.

Deixamos uma nota final sobre a importância deste levantamento: ao longo dele foi possível detetar (e corrigir) várias inconsistências na classificação das construções, o que é perfeitamente natural num objeto com esta dimensão e granularidade. A classificação sintático-semântica do Léxico-Gramática das construções verbais é, essencialmente, uma abordagem formal. A introdução de papéis semânticos (algo que quase não tem sido feito neste quadro teórico, pelo menos de um de modo explícito) e de informações distribucionais mais finas deverá permitir não só o desenvolvimento de processos de estruturação semântica mais rigorosa de conjuntos de predicados semânticos, como também validar (e eventualmente corrigir) casos de classificação em que diferenças de interpretação foram colapsadas sob a mesma entrada.

\section{A construção de verbum dicendi}

Outra propriedade que, consideramos, permite delimitar melhor o conceito de predicado de comunicação é a construção de verbum dicendi. Trata-se, como já se disse, de verbos que podem introduzir discurso direto, observando-se amiúde a inversão de sujeito (o locutor) e até, eventualmente, a expressão do complemento que designa o interlocutor. Considere-se este primeiro exemplo:

(16a) O Pedro disse ao João que não fazia mais isso

[Vdic] = (16b) Não faço mais isso! -, disse o Pedro (ao João) 
Predicados de comunicação em português europeu: nominalizações e nomes autónomos

Contudo, não se observam aqui apenas os verbos declarativos, como dizer, da classe 09I ou construções semelhantes (09C e 06, que vimos atrás), havendo numerosos casos de empregos metafóricos de outros verbos que admitem ser usados nesta construção ${ }^{8}$. Por exemplo:

(17) Não faço mais isso!, disparou/atirou o Pedro (ao João)

(18) Não faço mais isso!, cacarejou/rugiu o Pedro (ao João)

Portanto, a propriedade de agente-locutor e a de aceitação da construção Vdic são duas propriedades independentes. dicendi:

Verificou-se que 242 das entradas com sujeito agente-locutor apresentam uma construção de verbo

(19a) O Pedro afirma ao João que a Ana é uma pessoa competente [09I]

$=[$ Vdic $]$ (19b) A Ana é uma pessoa competente -, afirmou o Pedro (ao João)

Há, porém, 73 entradas com sujeito agente-locutor em que não se verifica a construção Vdic, e.g.

(20a) O Pedro omitiu ao João que a Ana tinha feito isso [09I]

(20b) *A Ana fez isso, omitiu o Pedro (ao João)

$\mathrm{Na}$ Tabela 2, apresentamos a distribuição das construções com sujeito agente-locutor em que não se verifica a construção de verbo dicendi.

\begin{tabular}{|c|c|c|c|}
\hline Classes & $\mathbf{n}^{\mathbf{0}}$ de construções & Classes & $\mathbf{n}^{\mathbf{0}}$ de construções \\
\hline $\mathbf{0 6}$ & 1 (ventilar) & $\mathbf{3 5 R}$ & 5 \\
\hline $\mathbf{0 8}$ & 3 & $\mathbf{3 5 S}$ & 9 \\
\hline $\mathbf{1 1}$ & $1($ chamar) & $\mathbf{3 6 D T}$ & 3 \\
\hline $\mathbf{1 3}$ & 1 (notificar) & $\mathbf{3 9 D}$ & 1 (chamar) \\
\hline $\mathbf{1 6}$ & 1 (culpabilizar) & $\mathbf{3 9 S}$ & 5 \\
\hline $\mathbf{4 0}$ & 1 (participar) & 39T & 17 \\
\hline
\end{tabular}

\footnotetext{
${ }^{8}$ A natureza metafórica destes empregos pode ser explicitada por meio de uma oração comparativa, em que se reconstitui o verbo dizer, como verbum dicendi genérico subjacente: Não faço mais isso!, disse o Pedro (ao João) como se estivesse a disparar (uma arma) / atirar (alguma coisa) / cacarejar / rugir. No caso dos verbos de vozes de animais, é transferida para o sujeito locutor uma propriedade saliente dos nomes de animais que são sujeitos particularmente apropriados a esses verbos: cacarejar: galinha (estupidez), rugir: leão (agressividade). De resto, este mesmo processo metafórico está na origem do emprego destes verbos como predicados de comunicação, i.e. sinónimos de dizer, mesmo fora da construção de verbo dicendi: O Escudeiro cacarejou ao cavalo (https://www.proz.com/); Eisenhower rugiu ao Departamento de Defesa que criasse uma "geringonça" (Correio da Manhã, 07/09/2008); ou até como variantes (muito criativas) de verbo-suporte de um nome que exprime um predicado de comunicação: a flácida Hipólita ... cacarejou um comando ao seu exército (https://articulacaoconservadora.org/ um-conto-chileno/).
} 


\begin{tabular}{|c|c|c|c|}
\hline 09C & 6 & 42S & 1 (falar) \\
\hline 09I & 12 & 32R & 3 \\
\hline 32R & 3 & Total & $\mathbf{7 3}$ \\
\hline
\end{tabular}

Tabela 2. Distribuição das construções com sujeito agente-locutor sem a construção Vdic.

Em relação às classes 09I e 09C, que são construções de que esperaríamos uma construção com Vdic, dado o perfil dos papéis semânticos envolvidos (locutor/mensagem/interlocutor ou, no caso da classe 09C, experimentador-volitivo (quem manda)/objeto-frásico (conteúdo ou ordem)/interlocutor), estes casos não admitem a construção de verbo dicendi. Por exemplo,

(21a) O Pedro provou à Ana que tinha razão

(21b) *Eu tinha razão —, provou o Pedro

(22a) O Pedro vedou à Ana que fizesse qualquer coisa

(22b) *Faz isso! —, vedou o Pedro à Ana

O valor performativo (pragmático) destes predicados, ainda que associados à noção de comunicação, deverá estar na origem desta interdição.

Há também um grupo importante das construções transitivas-predicativas que não admite a construção Vdic, provavelmente porque o sujeito não é claramente um locutor, mas sim um daqueles casos a que chamamos uma extensão do conceito de locutor. Veja-se os seguintes exemplos (classe 39x):

(23a) O Pedro chamou espertalhona à Ana

(23b) *(És uma) espertalhona —, chamou o Pedro

No caso da classe 35S, uma construção simétrica (e.g. conversar), talvez pelo facto de não selecionarem um objeto que seja conteúdo ou a mensagem, estes verbos não admitem, por isso, a construção Vdic:

(24a) O Pedro conversou com a Ana [35S]

(24b) *Acho isso importante -, conversou o Pedro (com a Ana)

Os restantes casos relevam, de algum modo, dos tipos acima indicados, ainda que as construções sintáticas na base da sua classificação formal variem bastante.

\section{Construções com nome predicativo}

Além das construções verbais, existem numerosos casos de nomes predicativos e verbos-suporte que exprimem predicados de comunicação, alguns dos quais são nominalizações de construções verbais. As construções nominais não parecem aceitar a construção Vdic:

(25a) O Pedro desabafou a/com a Ana que estava farto daquilo [09I]

= (25b) Estou farto disto, desabafou o Pedro (a/com a Ana)

(26a) O Pedro fez um desabafo a/com a Ana de que estava farto daquilo

= (26b) *Estou farto disto, fez o Pedro um desabafo (a/com a Ana) 
Quisemos, com este trabalho, verificar qual a extensão lexical dos predicados de comunicação expressos por nomes predicativos e verbos-suporte. Este estudo integra-se num programa mais vasto de construir um léxico-gramática dos nomes predicativos do português que ainda se encontra em curso, pelo que apresentamos apenas alguns resultados preliminares.

Do conjunto dos 5.535 nomes predicativos já sistematicamente descritos, 292 têm um agente-locutor. Como se vira nas construções verbais, o papel semântico de agente-locutor ocupa sempre a posição argumental de sujeito. Em primeiro lugar, destes, 176 são nominalizações, isto é, estão associadas transformacionalmente a construções verbais. Indicámos para cada uma destas construções a respetiva classe do ViPEr, para que fosse possível estabelecer um paralelo entre as construções nominais e as construções verbais equivalentes. Os resultados encontram-se na Tabela 3. De modo a podermos, com maior facilidade, identificar as diferenças entre o número de ocorrências de verbos com agente-locutor (Tabela 1) e o número de ocorrências de nomes predicativos que têm uma construção verbal correspondente (Tabela 3), mantiveram-se nesta última as classes verbais já apresentadas na primeira tabela.

\begin{tabular}{|c|c|c|c|c|c|c|c|}
\hline ClasseV & Npred & ClasseV & Npred & ClasseV & Npred & ClasseV & Npred \\
\hline $\mathbf{0 6}$ & 16 & $\mathbf{1 6}$ & 0 & $\mathbf{3 2 C}$ & 6 & 36R & 1 \\
\hline $\mathbf{0 7}$ & 1 & $\mathbf{4 0}$ & 1 & $\mathbf{3 2 H}$ & 23 & 39D & 0 \\
\hline $\mathbf{0 8}$ & 1 & $\mathbf{4 1}$ & 6 & $\mathbf{3 2 R}$ & 1 & $\mathbf{3 9 S}$ & 0 \\
\hline $\mathbf{1 0}$ & 0 & $\mathbf{0 9 C}$ & 18 & $\mathbf{3 5 R}$ & 6 & $\mathbf{3 9 T}$ & 3 \\
\hline $\mathbf{1 1}$ & 6 & $\mathbf{0 9 I}$ & 59 & $\mathbf{3 5 S}$ & 16 & $\mathbf{4 2 S}$ & 0 \\
\hline $\mathbf{1 3}$ & 9 & $\mathbf{0 9 R}$ & 1 & $\mathbf{3 6 D T}$ & 2 & Total & $\mathbf{1 7 6}$ \\
\hline
\end{tabular}

Tabela 3. Distribuição das construções nominais com sujeito agente-locutor com uma construção verbal associada.

Ao se estabelecer o paralelo entre as construções verbais e nominais, e na ausência de uma correspondência perfeita entre as duas estruturas, sobretudo em termos do perfil de papéis semânticos desse predicado, procurou-se sempre indicar para o verbo a classe do ViPEr correspondente, ainda que nem sempre a construção descrita fosse exatamente igual. Por exemplo, para o par apelar (classe 41) e fazer apelo, na descrição da construção nominal apenas se tinha retido o sujeito locutor e o interlocutor, ao passo que na descrição da construção verbal se tinha considerado haver dois complementos, nomeadamente um objeto-frásico como complemento oblíquo e um complemento indireto. É claro que a descrição da construção nominal estava incompleta, já que este complemento também pode aparecer com o nome predicativo, mantendo-se, inclusive, a restrição sobre a referência do sujeito da completiva-objeto (assinalada pelos índices $i$ de correferência):

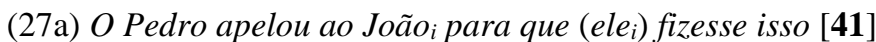

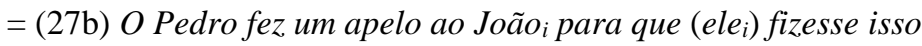

Estes casos foram todos assinalados com um código (\#) para posterior verificação e eventual correção. Ao todo, no caso das nominalizações, 118 construções apresentam algum tipo de diferença (número de argumentos, papéis semânticos, ou outras) e apenas 58 correspondem a uma equivalência mais perfeita: 
(28a) O Pedro anunciou a descoberta à comunidade científica [091]

= (28b) O Pedro fez o anúncio descoberta à comunidade científica

(29a) O Pedro elogiou a Ana $[\mathbf{3 2 H}]=(28 b)$ O Rui deulfez um elogio à Ana

Para certas classes de construções verbais, não se encontrou equivalente nominal. É o caso, por exemplo, do verbo barafustar (classe 10): O Pedro barafustou com o João que não queria ir ao cinema, para o qual não parece haver no léxico um nome predicativo correspondente (tal como se considera construções de nome predicativos autónomos, sem construções adjetivais ou verbais associadas, também há verbos 'isolados' para os quais a língua não oferece um equivalente nominal).

Noutros casos, embora haja um nome morfologicamente associado, a construção verbal não pode ser posta em relação transformacional com nenhuma das construções desse nome. É o caso da construção de chamar em 39D, e.g. O Pedro chamou parvo ao João, que não parece ter qualquer nominalização com os nomes morfologicamente relacionados, chamada ou chamamento. Repare-se que outras construções de chamar apresentam nominalização:

(30a) O Pedro chamou os alunos $=(29 b)$ O Pedro fez a chamada dos alunos

Nesta construção, o complemento (interlocutor/paciente) é o que chamamos uma posição de nome plural $(\mathrm{Npl})$, uma posição sintática para a qual o verbo seleciona um nome no plural ou um coletivo. A natureza $\mathrm{Npl}$ de um argumento é critério taxonómico para a constituição de algumas classes de construções verbais, o mesmo sucedendo no caso das frases com nome predicativo. A distinção torna-se mais nítida na construção nominal:

\section{(31) O Pedro chamou o aluno $=*$ O Pedro fez a chamada do aluno}

O ViPEr, contudo, neutraliza essa distinção ao classificar este emprego como 32H, sem dar conta da construção com complemento $\mathrm{Npl}$ (classe 32PL). Vemos assim, como outros autores já tinham referido anteriormente, que o estudo das nominalizações pode ser uma ferramenta poderosa no estabelecimento dos predicados, proporcionando distinções finas que, quando contemplados do ponto de vista de uma única categoria gramatical, não seria possível atingir.

Em contrapartida, encontrámos várias construções de nomes predicativos com sujeito locutor cujas nominalizações não estavam ainda descritas no ViPEr. Quisemos, por isso, averiguar a razão dessa lacuna. Foi o caso, por exemplo, de comprovação, que encontramos em

\section{(32a) A Ana deu uma comprovação/fez a comprovação ao Rui de que era honesta}

para o qual a única construção verbal registada se encontra na classe 01T e corresponde ao emprego:

(33a) O facto de o Pedro fazer isso comprova que ele já sabia do problema [01T]

o qual pode ser descrito como uma construção com completiva-sujeito (causa) e completiva-objeto (objeto-frásico). Haverá, pois, que completar o léxico-gramática dos verbos, integrando nele a construção de comprovar com a estrutura da classe 09I, v.g.:

$(32 \mathrm{a})=(31 \mathrm{~b})$ A Ana comprovou ao Rui que era honesta $[\mathbf{0 9 I}]$ 
À construção verbal 01T corresponderá, então, outro tipo de construção nominal, ainda que com o mesmo nome predicativo, como, por exemplo, com verbo-suporte ser, construção que também ainda não se encontrava descrita no léxico dos nomes, v.g.

\section{$(33 a)=(32 b)$ O facto de o Pedro fazer isso é a comprovação de que ele já sabia do problema}

Noutros casos, as relações de nominalização podem assumir contornos mais complexos. A construção de provocação, com complemento experimentador, está parcialmente relacionada com a construção 04 de provocar, e.g.

\section{(34a) O Rui fez uma provocação à Ana = (34b) O Rui provocou a Ana [04]}

mas a construção nominal apenas admite o sujeito agente, ao passo que a construção verbal admite também um sujeito com valor de causa, de natureza não-restrita (M. Gross, 1975; Nnr):

\section{(34c) Isso/o facto de o Pedro fazer isso provocou a Ana}

De um modo geral, aliás, as nominalizações das construções verbais de tipo psicológico (Mendes, 2004) apresentam este padrão.

Já em relação às construções dos nomes predicativos berraria, berreiro, berro e berros, a cujo sujeito atribuímos o papel semântico de agente-locutor, todas parecem poder associar-se à construção $\mathbf{3 1 H}$ de berrar . Contudo, cada forma parece apresentar uma nuance de significado que o verbo eclipsa. Note-se, no entanto, a variedade de construções sintáticas que estes nomes apresentam:

(35) O Pedro está em/fez um berreiro/uma berraria

(36a) O Pedro deu um berro/berros

(37a) O Pedro está aos berros

Neste último caso, a variação em número é bloqueada: *O Pedro está ao berro. Finalmente, repare-se que alguns destes nomes parecem exprimir um predicado semântico distinto, que autoriza um complemento dativo interlocutor:

(36b) O Pedro deu um berro/um par de berros ao João

(37b) O Pedro esteve aos berros com o João

Note-se, porém, as alternâncias: *O Pedro está em_um berreiro/uma berraria ao João, ?*O Pedro fez um berreiro/uma berraria ao João (o complemento dativo pode ser aqui um mero benefactivo, não essencial); $O$ Pedro está em_um berreiro/uma berraria com o João, ?O Pedro fez um berreiro/uma berraria com o João. (Uma situação semelhante ocorre com gritar e os nomes predicativos da mesma família: grito, gritaria). Há, pois, fundadas razões para se descrever a aparente polissemia de um verbo como berrar a partir do significado bem mais marcado ou distinto das suas nominalizações.

Vimos ainda que 116 das construções nominais já descritas correspondem a nomes predicativos autónomos, ou seja, nomes predicativos que não têm uma construção verbal ou adjetival correspondente como, por exemplo, o nome predicativo:

(38) O Pedro deu (as suas) condolências/ (os seus) pêsames ao João 
(39) O Pedro deu vivas aos noivos

(40) O Pedro fez uma serenata à Joana

(41) O Pedro esteve na má língua com o João

Entre os casos mais interessantes, até pela dificuldade em determinar a sua extensão lexical, estão os nomes que, apesar de morfologicamente relacionados com verbos, constituem construções independentes desses mesmos verbos. Assim, por exemplo, a par de gritar/dar um grito, encontramos

\section{(42) Este vestido é de gritos}

Noutros casos, a forma verbal encontra-se em franco desuso, como acontece com a nominalização do nome sermão em $O$ Pedro deu/pregou um sermão ao João, ainda que a construção verbal correspondente, ?*O Pedro sermoneou/sermonou o João, possa ainda encontrar-se:

"o ministro da Presidência ... sermone $[o u]$ os indígenas sobre as excelências do fairplay," (Correio da Manhã, 16/09/2007).

Noutras situações, em que o conceito de unidade lexical é levado ao limite, encontramos casos em que a construção verbal parece ter como nominalização um nome que hesitamos classificar como composto. Algumas destas entradas são as que se encontram associadas ao verbo jurar:

(43a) O Pedro jurou amor (eterno) à Ana

= (43b) O Pedro fez um juramento/uma jura de amor (eterno) à Ana

(44a) O Pedro jurou fidelidade à Ana = (43b) O Pedro fez um juramento/jura de fidelidade à Ana

Desde logo, a derivação do complemento direto da construção de jurar (09I), com completiva-objeto, para o nome não é evidente:

(45) O Pedro jurou à Ana (?que lhe teria) amor (eterno)/fidelidade

Ainda assim, a construção completiva é possível ainda que a variação jura/juramento não pareça completamente estabilizada. Noutros casos, a construção verbal já denota vários índices de fixidez, como sucede em jurar bandeira:

(46a) O Pedro jurou bandeira <nesta data>

= (46b) O Pedro fez/prestou (o) juramento de bandeira <nesta data $>$

não só pela impossibilidade de inserção de um complemento indireto (dativo), passando pela impossibilidade de derivar o complemento direto a partir de uma completiva, até à fixidez que se observa quanto ao determinante e modificador quer de juramento (que admite o determinante $o$ ), quer de bandeira (não podem ser inseridos quaisquer determinantes ou modificadores). Por estas razões, esta construção verbal poderia, com mais adequação, ser incluída no léxico das frases fixas (Galvão et al., 2019). Na nominalização, repare-se, também, na seleção do verbo-suporte prestar, que não parece ocorrer com a mesma naturalidade em ambos os casos antes referidos, nomeadamente, a par da variação prestar jura/juramento de fidelidade, verifica-se a restrição prestar jura/?*juramento de amor, pelo que jura de amor poderia, com vantagem, ser tratado como um nome composto. Ora, tal orienta a descrição das nominalizações para lá das (já de si complexas) relações entre 
construções verbais e nominais (enquanto palavras simples) para o quadro bem mais complexo das nominalizações de expressões fixas (M. Gross, 1986). Ficará para outra ocasião.

\section{Conclusões}

Este trabalho leva-nos a concluir que as propriedades de (i) sujeito com papel semântico de locutor e (ii) a possibilidade de entrar numa construção de verbum dicendi (Vdic) permitem delinear o conjunto de predicados verbais semanticamente bastante homogéneos a que chamamos predicados de comunicação. Contudo, estas duas propriedades são independentes, verificando-se tanto casos em que um verbo, claramente um predicado de comunicação do ponto de vista semântico, não aceita a construção Vdic (e.g. provar), bem como casos de verbos que ocorrem naquela construção (e.g. explodir), geralmente num sentido figurado, sem que, por outro lado, correspondam, num sentido literal, a predicados de comunicação.

Certas classes formais do léxico-gramática dos verbos são particularmente homogéneas do ponto de vista semântico relativamente à expressão dos predicados de comunicação (por exemplo, as classes 09I , e.g. confessar, e 09C, e.g. ordenar), que correspondem mais diretamente à definição típica deste tipo de predicação, envolvendo não só um sujeito locutor, mas igualmente um complemento direto interpretado como mensagem ou objeto-frásico e, no caso da classe 09I, um complemento dativo com valor de interlocutor. Há, contudo, numerosos outros verbos e de variadíssimas classes sintáticas que relevam do mesmo tipo de predicado semântico: e.g. telefonar, classe 33; cumprimentar, 32H; aludir, 07. Estes verbos apresentam, porém, diferente número de complementos e ou diferentes perfis semânticos (alinhamento de papéis semânticos), por vezes bem distintos do perfil mais típico que referimos acima. Por outro lado, até dentro da mesma classe formal de construções verbais encontramos predicados com diferentes perfis semânticos, por exemplo, envolvendo a variação entre paciente/interlocutor, cuja distinção nem sempre é fácil. Esta diversidade de estruturas sintáticas e de perfis semânticos, que surgem associadas ao mesmo tipo (genérico) de predicado (de comunicação), mostra como é difícil delimitar classes semânticas de objetos a partir das suas propriedades formais (sintáticas).

Em relação às construções predicativas nominais, os dados já disponíveis permitem verificar que um número considerável de nomes predicativos também pode exprimir predicados de comunicação, selecionando um sujeito locutor. Contudo, as construções com verbo-suporte não admitem a construção Vdic. Verifica-se frequentemente uma elevada autonomia das construções nominais relativamente às construções verbais que lhe estão associadas, fenómeno já referido na literatura (Ranchhod, 1990; Baptista, 2005), e que é particularmente notória nesta classe de predicados, já que o nome predicativo nem sempre conserva o conjunto de argumentos da construção verbal equivalente. A par das nominalizações, encontramos também numerosos casos (cerca de $30 \%$ ) de nomes predicativos autónomos, o que poderá ser um sinal da expressividade deste tipo de construções.

O mapeamento minucioso das propriedades das construções nominais nas que se observa nas construções verbais (e vice-versa) permitiu-nos não só constituir um léxico das expressões que exprimem atos comunicativos como também corrigir alguns problemas de representação que se observaram nas respetivas bases de dados, tanto das construções verbais como das construções com nome predicativo e verbo-suporte.

Agradecimentos: Parte da investigação para este artigo foi financiada com fundos públicos através da Fundação para a Ciência e a Tecnologia (ref. UIDB/50021/2020).

\section{Referências}

Baptista, Jorge (2001) Sintaxe dos predicados nominais construídos com o verbo-suporte ser de. Tese de doutoramento, Universidade do Algarve. 
Baptista, Jorge (2005a) Sintaxe dos predicados nominais com ser de. Lisboa: Fundação Calouste Gulbenkian/Fundação para a Ciência e a Tecnologia.

Baptista, Jorge (2005b) Construções simétricas: argumentos e complementos. Estudos de homenagem a Mário Vilela, pp. 353-367.

Baptista, Jorge (2010) Verba dicendi: A structure looking for verbs. In. T. Nakamura, É. Laporte, A. Dister, \& C. Fairon (Eds.) Les Tables. La grammaire du français par le menu. Mélanges en hommage à Christian Leclère. Louvain-la-Neuve: CENTAL/Presses Universitaires de Louvain, pp. 11-20.

Baptista, Jorge (2012) ViPEr: A Lexicon-Grammar of European Portuguese Verbs. In. J. Radimsky (Ed.), Proceedings of the $31^{\text {st }}$ international conference on lexis and grammar. Nové Hrady (Czech Republic), Università degli Studi di Salerno (Italy)/University of South Bohemia in Nové Hrady (Czech Republic), pp. 10-16.

Baptista, Jorge (2013) ViPEr: uma base de dados de construções léxico-sintáticas de verbos do português europeu. In. F. Silva, I. Falé, \& I. Pereira (Eds.) Actas do XXVIII Encontro da APL - Textos Selecionados. Lisboa: APL/Colibri, pp. 111-129.

Baptista, Jorge \& Nuno Mamede (2020a) Dicionário gramatical de verbos do português. Faro: Universidade do Algarve Editora.

Baptista, Jorge \& Nuno Mamede (2020b) Syntactic Transformations in Rule-Based Parsing of Support Verb Constructions: Examples from European Portuguese. SLATE, Jul 2020, Barcelos (virtual), Portugal.

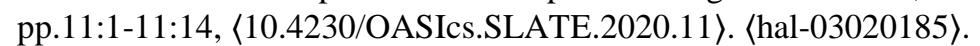

Bick, Eckhard (2007) Automatic Semantic Role Annotation for Portuguese. In. Proceedings of TIL $2007-5^{\text {th }}$ Workshop on Information and Human Language Technology /Anais do XXVII Congresso da SBC, pp. 1713-1716.

Calcia, Nathalia (2016) Descrição e classificação das construções conversas do Português do Brasil. Dissertação de mestrado, Universidade Federal de São Carlos.

Cançado, Márcia (2012) Manual de Semântica: noções básicas e exercícios. São Paulo: Contexto.

Cançado, Márcia \& Anabela Gonçalves (2016) Lexical Semantics: Verb Classes and Alternations. In. W. Leo Wetzels, João Costa \& Sergio Menuzzi (Eds.) The Handbook of Portuguese Linguistics. UK: Wiley Blackwell, pp. 374-391.

Cançado, Márcia \& Luana Amaral (2017) Introdução à semântica lexical: papéis temáticos, aspecto lexical e decomposição de predicados. Petrópolis: Editora Vozes Limitada.

Chacoto, Lucília (2005) O verbo fazer em construções nominais predicativas. Tese doutoramento, Universidade do Algarve.

Costa, Bianca \& Cláudia Freitas (2017) Verbos de elocução em português: um estudo descritivo com base em grandes corpora e motivado pela Linguística Computacional. Fórum Linguístico 14 (3), pp. 2266-2285.

Costa, Bianca \& Cláudia Freitas (2019) Um léxico de verbos do dizer para tradutores - e considerações sobre a classificação dos verbos de elocução. Calidoscópio, 17 (3), pp. 494-515.

Couto, Marcella \& Mário Perini (2016) Verbos de comunicação ou construções de comunicação? Uma análise através da noção de valência verbal. Cadernos do CNLF (Congresso Nacional de Linguística e Filologia) XX (3) - Ensino de língua e literatura, Rio de Janeiro: Círculo Fluminense de Estudos Filológicos e Linguísticos, pp. 270-280.

Cunha, Celso \& Lindley Cintra (1984) Nova Gramática do Português Contemporâneo. (5ª ed. 1999) Lisboa: Edições Sá da Costa.

Dias-da-Silva, Bento \& Helio de Moraes (2003) A construção de um thesaurus eletrônico para o português do Brasil. ALFA 47 (2), pp. 101-115.

Dias de Barros, Cláudia (2014) Descrição e classificação dos predicados nominais com o verbo-suporte fazer em Português do Brasil. Tese de doutoramento, Universidade Federal de São Carlos. 
Dowty, David (1991) Thematic Proto-Roles and Argument Selection. Language 67 (3), pp. 547-619.

Duarte, Isabel (2020) Discurso relatado. In. Eduardo Raposo, Maria Bacelar do Nascimento, Maria Mota, Luísa Segura, Amália Mendes \& Amália Andrade (Coord.) Gramática do Português, vol. III. Lisboa: Fundação Calouste Gulbenkian, pp. 2589-2613.

Garcia, Othon (2011) Comunicação em prosa moderna (27ª edição). Rio de Janeiro: Editora FGV.

Gildea, Daniel \& Daniel Jurafsky (2002) Automatic labeling of semantic roles. Computational linguistics, 28 (3), pp. 245-288.

Perini, Mário (2015) Describing Verb Valency. Pratical and Theoritical Issues. Cham, Switzerland: Springer New York.

Fillmore, Charles (1968) The case for case. In. E. Bach, \& R. T. Harms (Eds.), Universals in linguistic theory. New York, NY: Holt, Rinehart, and Winston, pp. 1-88.

Galvão, Ana, Jorge Baptista \& Nuno Mamede (2019) New developments on processing European Portuguese verbal idioms. In. Carlos Augusto Prolo \& Leandro Henrique Mendonça de Oliveira (Eds.), $12^{\text {th }}$ Symposium in Information and Human Language Technology, Salvador, BA (Brazil), October 15-18 2019, pp. $229-238$.

Gross, Gaston (1989) Les constructions converses du français. Langue et cultures, 22. Travaux du Laboratoire de Linguistique Informatique. Librairie Droz: Genève-Paris.

Gross, Maurice (1975) Méthodes en syntaxe. Régime des constructions complétives. Paris: Hermann.

Gross, Maurice (1981) Les bases empiriques de la notion de prédicat sémantique. Langages 63, Paris: Larousse, pp. 7-52 e 127-128.

Gross, Maurice (1986) Les nominalisations d'expressions figées. Langue française. 69, Paris: Larousse.

Gross, Maurice (1988) Methods and tactics in the construction of a lexicon-grammar. Linguistics in the morning calm 2. Select papers from SICOL 1986, Hanshin Publishing Company, Seoul, pp. 177-197.

Gross, Maurice (1996) Grammaire Transformationnelle du Français. Syntaxe de l'adverbe. Paris: ASSTRIL

Harris, Zellig (1991) A Theory of Language and Information - A Mathematical Approach. Oxford: Clarendon Press.

Levin, Beth (1993) English Verb Classes and Alternations: A Preliminary Investigation. Chicago: University of Chicago Press.

Mamede, Nuno, Jorge Baptista, Cláudio Diniz \& Vera Cabarrão (2012) STRING - A Hybrid Statistical and Rule-Based Natural Language Processing Chain for Portuguese. In PROPOR 2012 - Demo: http://www.propor2012.org/demos/DemoSTRING.pdf.

Marrafa, Palmira (2002) Portuguese WordNet: general architecture and internal semantic relations. DELTA, 18, pp. 131-146.

Maziero, Erick, Thiago Pardo, Ariani Di Felippo \& Bento Dias-da-Silva (2008) A Base de Dados Lexical e a Interface Webdo TeP 2.0 - Thesaurus Eletrônico para o Português do Brasil. In VI Workshop em Tecnologia da Informação e da Linguagem Humana (TIL), pp. 390-392.

Mendes, Amália (2004) Predicados verbais psicológicos do português. Lisboa: Fundação Calouste Gulbenkian/Fundação para a Ciência e a Tecnologia.

Oliveira, Hugo, Diana Santos \& Paulo Gomes (2010) Extracção de relações semânticas entre palavras a partir de um dicionário: o PAPEL e sua avaliação. Linguamática 2 (1), pp. 77-93.

Oliveira, Hugo \& Paulo Gomes (2014) ECO and Onto.PT: A flexible approach for creating a Portuguese wordnet automatically. In. Language Resources and Evaluation 48 (2), Springer, pp. 373-393.

Oliveira, Sofia, Daniel Loureiro \& Alípio Jorge (2021) Transformers and Transfer Learning for Improving Portuguese Semantic Role Labeling. arXiv preprint arXiv:2101.01213.

Paiva, Valeria, Alexandre Rademaker \& Gerard de Melo (2012) OpenWordNet-PT: An Open Brazilian WordNet for Reasoning. In Proceedings of $24^{\text {th }}$ International Conference on Computational Linguistics, COLING (Demo Paper). 
Pesetsky, David (1995) Zero Syntax. Cambridge, MA: MIT Press.

Ranchhod, Elisabete (1990) Sintaxe dos predicados nominais com ESTAR. Lisboa: INIC - Instituto Nacional de Investigação Científica.

Rassi, Amanda (2015) Descrição, classificação e processamento automático das construções com o verbo 'dar' em português brasileiro. Tese de doutoramento, Universidade Federal de São Carlos.

Rocha, Paulo \& Diana Santos (2000) CETEMPúblico: Um corpus de grandes dimensões de linguagem jornalística portuguesa. In. M. G. Volpe Nunes (Ed.) Actas do V Encontro para o processamento computacional da língua portuguesa escrita e falada (PROPOR'2000), (Atibaia, São Paulo, Brasil, 19 a 22 de Novembro de 2000), pp. 131-140.

Santos, Maria (2015) Descrição dos predicados nominais com o verbo-suporte 'ter'. Tese de doutoramento, Universidade Federal de São Carlos.

Scher, Ana (2004) As construções com o verbo leve DAR e nominalizações em -ADA no Português do Brasil. Tese de doutoramento, Universidade Estadual de Campinas.

Simões, Alberto \& Xavier Gómez Guinovart (2014) Bootstrapping a Portuguese wordnet from Galician, Spanish and English wordnets. In. Advances in Speechand Language Technologies for Iberian Languages, vol. 8854, Springer, pp. 239-248.

Sousa, Isis \& Oto Vale (2006) Dicionário eletrônico de formas verbais compostas do português do Brasil: verbos de comunicação e expressão cristalizada. In. Congresso de pesquisa, ensino e extensão da UFG- conpeex, 3, 2006, Goiânia. Anais eletrônicos de XIV Seminário de Iniciação científica [CD-ROM], Goiânia: Universidade Federal de Goiás.

Talhadas, Rui, Nuno Mamede \& Jorge Baptista (2013) Semantic roles for Portuguese verbs. In Proceedings of $32^{\text {nd }}$ International Conference on Lexis and Grammar, Faro: Universidade do Algarve, pp. 127-132.

Talhadas, Rui (2014) Automatic Semantic Role Labeling for European Portuguese. Dissertação de Mestrado, Universidade do Algarve. 


\begin{tabular}{|c|c|c|}
\hline Classe & Estrutura & Exemplo \\
\hline 06 & Humo $_{0}$ VueF ${ }_{1}$ & O Rui pensa que o João é inteligente. \\
\hline 07 & $\operatorname{Hum}_{0} V$ a $\operatorname{Vinf}_{1}^{0}$ & O Rui aprendeu a fazer isso. \\
\hline 08 & $N_{0} \operatorname{VPrep}_{1} \mathrm{QueF}_{1}$ & O Rui dependia da autorização do João. \\
\hline 09C & Hum $_{0}$ V QueFconj a Hum $_{2}$ & O Rui ordenou ao João que fizesse isso. \\
\hline 09I & Hum $_{0}$ V QueFind a Hum $_{2}$ & O Rui disse ao João que estava feliz. \\
\hline 09R & $\mathrm{Hum}_{0} \mathrm{VQueF_{1 }}$ a Hum $_{2}$ & O Rui perguntou ao João se (ele) estava feliz. \\
\hline 10 & Humo V QueF 1 Prep2 Hum $_{2}$ & O Rui barafustou com o João que não queria pagar isso. \\
\hline 11 & $N_{0} V N_{1}$ a $Q u e F_{2}$ & O Rui obrigou o João a fazer isso. \\
\hline 13 & $N_{0} V_{1}$ de $Q u e F_{2}$ & O Rui informou o João de que ia fazer isso. \\
\hline 16 & $N_{0} V Q_{u e F_{1}}$ Prep $_{2} Q_{u e F_{2}}$ & O Rui deduziu isso daquilo. \\
\hline 32H & Humo V Hum $_{1}$ & O Rui ama a Ana. \\
\hline 32R & $N_{0} V N c_{1}$ & O Rui estrelou um ovo. \\
\hline $32 \mathrm{C}$ & $N_{0} V(H u m+n H u m)_{1}$ & O Rui leu um livro. \\
\hline $35 S$ & $\operatorname{Nsim}_{0} \operatorname{VPrep} \operatorname{Psim}_{1}$ & O Rui conversou com o João. \\
\hline $35 R$ & $N_{0} \operatorname{VPrep}_{1} N_{1}$ & O Rui confia no João. \\
\hline 36DT & Humo V Nobji a Hum & O Rui deu um livro ao João. O Rui roubou um livro ao João. \\
\hline 39D & $\mathrm{N}_{0} \mathrm{VNtag}_{1} \mathrm{a} \mathrm{N}_{2}$ & O Rui chamou parvo ao João. \\
\hline $39 S$ & $N_{0}$ V-se $\left(\right.$ Prep $\left._{I}\right)$ Ntag $_{I}$ & O Rui arvorou-se em defensor dos fracos. \\
\hline $39 \mathrm{~T}$ & $\mathrm{~N}_{0} \mathrm{VN}_{1}\left(\mathrm{Prep}_{2}\right) \mathrm{Ntag}_{2}$ & O Rui nomeou o João (como) seu sucessor. \\
\hline 40 & $N_{0} V \operatorname{Prep}_{1} N_{1} \operatorname{Prep}_{2} N_{2}$ & O Rui deu com um livro na cabeça do João. \\
\hline 41 & $N_{0} V_{P^{2 e p}} N_{1}$ Prep $_{2} Q_{u e F_{2}}$ & O Rui apelou ao João para que fizesse isso. \\
\hline $42 S$ & $\operatorname{Nsim}_{0} \operatorname{VPrep}_{1} \operatorname{Nsim}_{1} \operatorname{Prep}_{2} \mathrm{~N}_{2}$ & O Rui comungava com o João dos mesmos ideais. \\
\hline
\end{tabular}

Tabela 4. Classes ViPEr referidas no documento (retirada de Baptista \& Mamede, 2020a)

Convenções: Hum: nome humano, $n H u m$ : nome não-humano, $N c$ : nome distribucionalmente bastante restrito, Nobj: nome com papel semântico de objeto, Ntag: constituite com o papel semântico de etiqueta ( epíteto) nas construções transitivaspredicativas, $N_{i}$ : grupo nominal (os índices 0,1 e 2 indicam, respetivamente, o sujeito, e o primeiro e segundo complemento do verbo), Nsim: nomes numa relação de simetria, Prepi: preposição (o índice $i$ indica o complemento), QueF: oração subordinada completiva (-ind: modo indicativo, -conj: modo conjuntivo), $V$ : verbo, Vinf $e_{i}$ : oração infinitiva (o índice $i$ indica o complemento verbal e o expoente $e$ a correferência do sujeito do infinitivo com um constituinte do verbo principal). 